\title{
Calcium and Potassium Channels in Experimental Subarachnoid Hemorrhage and Transient Global Ischemia
}

\author{
Marcel A. Kamp, ${ }^{1,2}$ Maxine Dibué, ${ }^{1,2,3}$ Toni Schneider, ${ }^{2,3}$ \\ Hans-Jakob Steiger, ${ }^{1}$ and Daniel Hänggi ${ }^{1}$ \\ ${ }^{1}$ Department for Neurosurgery, Medical Faculty, Heinrich Heine University, Moorenstraße 5, 40225 Düsseldorf, Germany \\ ${ }^{2}$ Institute for Neurophysiology, University of Cologne, Robert-Koch-Straße 39, 50931 Cologne, Germany \\ ${ }^{3}$ Center of Molecular Medicine, Cologne, Germany
}

Correspondence should be addressed to Marcel A. Kamp, marcelalexander.kamp@med.uni-duesseldorf.de

Received 19 September 2012; Accepted 27 October 2012

Academic Editor: R. Loch Macdonald

Copyright (c) 2012 Marcel A. Kamp et al. This is an open access article distributed under the Creative Commons Attribution License, which permits unrestricted use, distribution, and reproduction in any medium, provided the original work is properly cited.

\begin{abstract}
Healthy cerebrovascular myocytes express members of several different ion channel families which regulate resting membrane potential, vascular diameter, and vascular tone and are involved in cerebral autoregulation. In animal models, in response to subarachnoid blood, a dynamic transition of ion channel expression and function is initiated, with acute and long-term effects differing from each other. Initial hypoperfusion after exposure of cerebral vessels to oxyhemoglobin correlates with a suppression of voltage-gated potassium channel activity, whereas delayed cerebral vasospasm involves changes in other potassium channel and voltage-gated calcium channels expression and function. Furthermore, expression patterns and function of ion channels appear to differ between main and small peripheral vessels, which may be key in understanding mechanisms behind subarachnoid hemorrhage-induced vasospasm. Here, changes in calcium and potassium channel expression and function in animal models of subarachnoid hemorrhage and transient global ischemia are systematically reviewed and their clinical significance discussed.
\end{abstract}

\section{Introduction}

Despite current treatment options, delayed cerebral ischemia following aneurismal subarachnoid hemorrhage ( $\mathrm{SAH})$ is still associated with a high morbidity and mortality [1]. The narrowing of cerebral blood vessels by vasospasm represents the main cause of delayed cerebral ischemia [2]. Because vasospastic smooth muscle cells are known to be depolarized compared to controls $[3,4]$, the expression and function of ion channels in these cells after $\mathrm{SAH}$ are of great interest. Furthermore, the inhibitor of Ltype calcium channels nimodipine remains gold standard in treatment and prophylaxis of vasospasm after SAH. However, recent studies have revealed that several ion channels of different subfamilies are impacted by SAH and may contribute to delayed vasospasm. The goal of the present analysis is to review ion channel expression and function in healthy cerebral blood vessels as well as after SAH.

\section{Ion Channels Healthy Cerebral Vessels}

2.1. Expression and Function of Potassium Channels in Healthy Cerebral Vessels. Membrane potential of cerebrovascular smooth muscle cells and thus dilation and constriction of cerebral arteries are directly dependent on potassium conductance $[5,6]$. Members of four potassium superfamilies have been shown to be expressed in smooth muscle cells of healthy cerebral vessels: inwardly rectifying $\left(\mathrm{K}_{\mathrm{ir}}\right)$, ATP-dependent- $\left(\mathrm{K}_{\mathrm{ATP}}\right)$, voltage-gated $\left(\mathrm{K}_{v}\right)$, and largeconductance calcium-activated (BK) potassium channels. $\mathrm{K}_{\mathrm{ir}} 2.1 \mathrm{mRNA}$ and protein could be identified in basilar arteries of rats and dogs $[7,8]$, whereas the presence of $\mathrm{K}_{\text {ATP }}$ in cerebrovascular smooth muscle has been determined electrophysiologically [9] and reviewed in detail by Ploug et al. 2008 [10]. Transcripts of $\mathrm{K}_{v}$ channel subunits $\mathrm{K}_{v} 1.1$ to $\mathrm{K}_{v} 1.6, \mathrm{~K}_{v} 2.1, \mathrm{~K}_{v} 2.2$, were detected in healthy rat cerebral vessels and $\mathrm{K}_{v} 3.1, \mathrm{~K}_{v} 3.4$, and $\mathrm{K}_{v} 4.3$ in healthy dog cerebral vessels but only protein of $\mathrm{K}_{v} 1.2, \mathrm{~K}_{v} 1.5, \mathrm{~K}_{v} 2.1$, and $\mathrm{K}_{v} 2.2$ 
subunits could be identified $[7,11,12]$. In situ hybridization revealed the presence of different $\mathrm{BK}$ channel splice variants $\left(\mathrm{X} 1_{+24}, \mathrm{X} 2_{+92}, \mathrm{SS} 2_{+174}\right.$ and $\left.\mathrm{SS} 4_{+81}\right)$ in combination with $\beta 1, \beta 2$, and $\beta 4$ subunits in rat cerebral arteries [13]. Transcripts of both $K_{\mathrm{ir}} 2.1$ and $\mathrm{K}_{\mathrm{ir}} 2.2$ have been identified in cerebrovascular smooth muscle $[14,15]$, where they are thought to play an essential role in neurovascular coupling by mediating local vasodilation as a response to increased neuronal activity [16-18].

Functional studies of the physiological role of $\mathrm{K}_{v}$ and BK channels in healthy cerebral vessels show that they contribute to vascular tone by regulating resting membrane potential of vascular myocytes, limiting depolarization by promoting $\mathrm{K}^{+}$efflux [19]. BK channels are particularly vital in cerebral resistance arteries, where raised intracellular calcium at depolarization elicits outward BK currents representing a negative feedback loop, which antagonizes vasoconstriction $[20,21]$. Furthermore, BK channels also play an important role in the principle vasorelaxation pathway (nitric oxide synthase pathway), as they are activated by cyclic GMPdependent protein kinase (PKG), which is stimulated by the NO-induced increase of cGMP [22]. Interestingly, a recent study of mouse cerebral parenchymal arterioles found small-conductance (SK) and intermediate-conductance (IK) calcium-activated potassium currents in isolated endothelial cells in addition to the BK currents in isolated myocytes [23]. Both appear to contribute to vasorelaxation, as superfusion of the cerebral cortex with SK and IK channel inhibitors apamin and TRAM-34, respectively, reduces resting cortical CBF [23].

In healthy cerebral blood vessels activation of $\mathrm{K}_{\mathrm{ATP}}$ channels causes hyperpolarization of vascular myocytes and thus vasodilatation [5, 18, 19]. Several antihypertensive drugs like the vasodilators diazoxide, cromakalim, and pinacidil exert their therapeutic effect by activating $\mathrm{K}_{\text {ATP }}$ channels $[24,25] . K_{\text {ATP }}$ channels appear to play an important role in cerebral autoregulation, as in rats their inhibition impairs healthy autoregulatory vasomotor responses to hypotension and its reverse. Furthermore, $\mathrm{K}_{\mathrm{ATP}}$ channel activation is also associated with several pathophysiological responses such as reactive hyperemia in cerebral circulation after hypoxia [26] (reviewed by Ko et al., 2008 [27]).

\subsection{Expression and Function of Calcium Channels in Healthy} Cerebral Vessels. L-type voltage-gated calcium channels (VGCCs) were traditionally believed to predominantly control $\mathrm{Ca}^{2+}$ influx in cerebrovascular smooth muscle cells; however recent studies have revealed expression of various $\mathrm{Ca}^{2+}$ channels and their isoforms. Protein and transcripts of the alpha1 subunit of the $\mathrm{Ca}_{v} 1.2$ (L-type) VGCC are expressed strongly in basilar arteries of the dog [28] and the rat [29]. Interestingly, however, in the rat basilar artery (and lateral branches), transcripts of the low-voltage activated channel $\mathrm{Ca}_{v} 3.1$ were the strongest expressed VGCCs, exceeding relative mRNA levels of the other four identified VGCCs in the following order: $\mathrm{Ca}_{v} 3.1$ (T-type) $>\mathrm{Ca}_{v} 1.2$ (L-type) $>\mathrm{Ca}_{v} 1.3$ (L-type) $>\mathrm{Ca}_{v} 3.2$ (T-type) $>\mathrm{Ca}_{v} 2.3$ (Rtype). The same study found that, at the protein level, $\mathrm{Ca}_{v} 3.1$ and $\mathrm{Ca}_{v} 1.2$ were both clearly expressed basilar artery smooth muscle cells, while $\mathrm{Ca}_{v} 3.2$ protein expression was much lower, $\mathrm{Ca}_{v} 2.3$ protein was confined to the surface of the vessel, and $\mathrm{Ca}_{v} 1.3$ protein was not detectable at all. However, the authors did not find evidence for $\mathrm{Ca}_{v} 2.2$ (N-type) VGCC protein or mRNA expression as was found in basilar arteries of the dog [28]. In dogs inhibition of L- and T-type $\mathrm{Ca}^{2+}$ channels with nimodipine and mibefradil, respectively leads to a relaxation of healthy arteries under isometric tension, whereas blockade, of $\mathrm{N}$-type $\mathrm{Ca}^{2+}$ channel has no effect [30].

It is notable that expression of VGCCs appears to be heterogeneous in cerebrovascular smooth muscle cells: in the dog basilar artery low-voltage activated (LVA) current made up more than $50 \%$ of the total current in $12 \%$ of myocytes, less than $10 \%$ in $26 \%$ of myocytes, and between $10 \%$ and $50 \%$ in $62 \%$ of myocytes [28]. Additionally VGCC expression may vary depending on vessel size: Kuo and coworkers [31] described a high-voltage-activated $\mathrm{Ca}^{2+}$ current showing $\mathrm{T}$ type channel kinetics, which is insensitive to nifedipine and nimodipine and is blocked by the T-type blocker mibefradil. Interestingly, the fraction of this current is higher in smaller vessels and decreases with vessel size. These currents could represent low-voltage-activated T-type currents, but also "intermediate-voltage-" activated R-type currents, which are insensitive to dihydropyridines but are also antagonized by mibefradil [32]. This vessel-size-dependent difference of expression patterns of VGCCs in cerebral blood vessels implies that the contribution of L-type VGCCs to vasoconstriction is greatest in large basal cerebral vessels, while dihydropyridine-insensitive VGCCs play a more important role in smaller vessels. Other investigators suggest that L-type $\mathrm{Ca}^{2+}$ channels could be responsible for vasomotion, while non-L-type $\mathrm{Ca}^{2+}$ channels control vascular tone [29].

\section{Early Ion Channel Dysfunction after SAH}

In addition to delayed cerebral vasospasms, acute hypoperfusion immediately after rupture of an aneurysm causing subarachnoid blood represents another characteristic of SAH pathology [33-35]. Relative hypovolemia, impaired cerebral circulation due to elevated intracranial pressure, abnormal autoregulation, as well as early vasospasm have been discussed as possible etiologies behind acute hypoperfusion after SAH [33, 35-38]. Some insights into the underlying molecular mechanism could be gained from animal experiments. Data from a rat SAH model found evidence for acute vasoconstriction after even minor subarachnoid hemorrhage [35]. In cultured primate cerebrovascular smooth muscle cells a significant increase of free intracellular $\mathrm{Ca}^{2+}$ is observed as early as 2 minutes after exposure to oxyhemoglobin (oxyHb) and sustains for 7 days [39]. Similarly Takenaka and colleagues found that endothelin, oxyHb, 5-hydroxytryptamine, norepinephrine, prostaglandin F2 alpha, and leukotrienes C4 and D4 but not bilirubin produced acute dose-dependent increases in intracellular $\mathrm{Ca}^{2+}$ concentration [40] in cultured cerebrovascular smooth muscle cells. Furthermore, Takenaka and coworkers report that the L-type $\mathrm{Ca}^{2+}$ channel blocker verapamil 
does not inhibit the oxyHb-induced rise in intracellular $\mathrm{Ca}^{2+}$, implying non-L-type calcium channels in acute vasoconstriction after exposure of the vessel to blood [41]. This finding may be explained by data from Ishiguro and coworkers [42] that demonstrates that, in isolated cerebral arteries, acute oxyHb exposure induces vasoconstriction and suppression of $\mathrm{K}_{v}$ currents but does not influence VGCCs. Long-term (5 days) oxyHb exposure on the other hand enhanced expression of VGCCs, pointing toward important roles of $\mathrm{K}_{v}$ channels in acute vasoconstriction and VGCCs in delayed vasoconstriction after SAH.

\section{Changes in Ion Channel Expression and Function in Delayed Cerebral Vasospasm}

\subsection{The Pathophysiological Role of Potassium Channels in the Genesis of Delayed Cerebral Vasospasm}

4.1.1. Voltage-Gated Potassium $\left(K_{v}\right)$ Channels in SAH. Reduced $\mathrm{K}^{+}$conductance causing depolarization of cerebrovascular myocytes was amongst the earliest hypotheses behind delayed cerebral vasospasm after $\mathrm{SAH}$, and indeed many modern studies support this model [43-45]. However, it has become increasingly evident that members of different potassium channel families are affected in different ways after SAH, raising many new questions. Several authors emphasize a loss of functional voltage-gated $\mathrm{K}^{+}$channel $\left(\mathrm{K}_{v}\right)$ in response to $\mathrm{SAH}$, as mainly responsible for the disturbance of $\mathrm{K}^{+}$conductance. Seven days after $\mathrm{SAH}, \mathrm{K}_{v} 2.2$, and $\mathrm{K}_{v} 2.1$ transcripts and protein were found to be reduced in basilar arteries of dogs [7, 43]. Immunohistochemical staining of rabbit cerebral arteries revealed a reduction of surface-expressed $\mathrm{K}_{v} 1.5$ protein 5 days after oxyHb exposure [46]. Furthermore, Ishiguro describes redistribution of $\mathrm{K}_{v} 1.5$ protein after oxyHb exposure: in unexposed vessels $\mathrm{K}_{v} 1.5$ was observed within large defined regions of the cell membrane and was associated with phosphotyrosine-rich vesicular compartments adjacent to the plasma membrane, whereas OxyHb exposure caused a decrease in $\mathrm{K}_{v} 1.5$ surface staining and a redistribution of the remaining $\mathrm{K}_{v} 1.5$ into smaller foci that appeared fused with phosphotyrosine-enriched vesicles. This stands in support of the hypothesis that oxyHbinduced suppression of $\mathrm{K}_{v} 1.5$ channels is mediated by a mechanism involving increased tyrosine phosphorylationdependent trafficking of the channel from the cell surface [46].

4.1.2. Inwardly Rectifying Potassium ( $K_{\text {ir }}$ ) Channels in SAH. Next to $K_{v}$ channels, expression of an inwardly rectifying potassium channel is found to be influenced by SAH. Seven days after $\mathrm{SAH}$, dog basilar artery myocytes display enhanced expression of $\mathrm{K}_{\mathrm{ir}} 2.1$ protein and transcripts [7, 45]. Accordingly, blockage of $\mathrm{K}_{\mathrm{ir}} 2.1$ channels in arteries under isometric tension produced a greater contraction in $\mathrm{SAH}$ than in control arteries. It is thus possible that increased expression of $\mathrm{K}_{\mathrm{ir}} 2.1$ channels after SAH may represent an adaptive response reducing disturbance of the cellular $\mathrm{K}^{+}$ balance and consecutively cerebral vasospasm.
4.1.3. Large Conductance Calcium-Activated (BK) Potassium Channels in SAH. Whether BK channels are impacted by SAH and contribute to vasospasm is a matter of debate, as data on this subject has proven to be somewhat contradictory. It has been reported that in dog basilar artery myocytes, BK current density, kinetics, $\mathrm{Ca}^{2+}$ and voltage sensitivity, single-channel conductance, and apparent $\mathrm{Ca}^{2+}$ affinity are unaffected by SAH [44]. Aihara et al. report that although the expression of the BK channel alpha subunit is unchanged after $\mathrm{SAH}$, expression of BK channel $\beta 1$ subunit mRNA (but not protein) is reduced 7 days after SAH in dog basilar artery myocytes and correlates with the degree of vasospasm [7]. Koide et al. found that although SAH does not alter BK channel density or single channel properties in rabbits, SAH does cause a distinct reduction in $\mathrm{Ca}^{2+}$ sparkinduced transient BK currents, corresponding to decreased expression of ryanodine receptor type-2 protein [47]. $\mathrm{Ca}^{2+}$ sparks are focal $\mathrm{Ca}^{2+}$ releases through ryanodine receptors (RyRs) in the sarcoplasmic reticulum (SR), which oppose the contractile actions of global cytosolic $\mathrm{Ca}^{2+}$ by activation of BK channels leading to hyperpolarization and decreased $\mathrm{Ca}^{2+}$ influx through VGCCs $[48,49]$. Findings by Koide et al. suggest that impaired subcellular signaling from the SR to BK channels at the cell surface, due to reduced expression of RyRs causing less focal $\mathrm{Ca}^{2+}$ spark discharges, could be a key mechanism in vasospasm after $\mathrm{SAH}$.

4.1.4. ATP-Dependent $\left(K_{A T P}\right)$ Potassium Channels in SAH. An important role of $K_{A T P}$ channels in animal models of $\mathrm{SAH}$-induced vasospasm appears likely, as several experimental studies have shown that pharmacologic activation of $\mathrm{K}_{\mathrm{ATP}}$ channels can significantly attenuate vasospasm. The $\mathrm{K}_{\text {ATP }}$ channel activator levcromakalim increased vasorelaxation in rabbit basilar arteries three days after SAH [4] and in dog basilar arteries seven days after SAH [50]. Furthermore, the endogenous $\mathrm{K}_{\mathrm{ATP}}$ channel activator calcitonin generelated peptide (CGRP) displayed therapeutic effects reversing vasospasm after SAH in rabbits and monkeys $[51,52]$ but failed to significantly attenuate vasospasm to a greater degree than standard of care (nimodipine) in a clinical trial comprising 117 patients [53].

4.1.5. VGCCs in SAH. The role of VGCCs in vasospasm may seem obvious in clinical practice where L-type $\mathrm{Ca}^{2+}$ channel blockers, such as nimodipine, are the gold standard of prophylaxis and treatments of cerebral vasospasm. This is indeed reflected in experimental investigations offering evidence in support of a large contribution of L-type VGCCs to vasoconstriction in certain cerebral blood vessels. However, recent findings have revealed the importance of Rtype and T-type channels in vasospasm. Although typically classed with the high-voltage-activated $\mathrm{Ca}^{2+}$ channels, $\mathrm{R}-$ type calcium channels are activated at potentials between those of low and high VGCCs, representing an intermediate VGCC. This channel is of interest in vasospasm, as its expression is directly linked to $\mathrm{SAH}$ and it may be available for opening at the depolarized resting potential of vasospastic cerebrovascular myocytes. 
Intravenous administration of nimodipine five minutes after SAH improves circulation and attenuates vasospasm in rats [54]. Nicardipine (dihydropyridine) pellets positioned next to the basal arteries have been shown to reduce the occurrence of angiographic vasospasm in a dose-dependent manner in patients suffering from SAH [55, 56]. However, L-type antagonists alone cannot reverse SAH-induced vasospasm completely. In this regard, the finding is that although L-type VGCC antagonists abolish cerebral artery constriction and block VGCC currents in cerebral artery myocytes from healthy rabbits, the lack of their efficacy in rabbits after SAH corresponds to an increase in R-type currents and $\mathrm{alpha}_{1 \mathrm{E}}\left(\mathrm{Ca}_{v} 2.3\right.$ pore forming subunit) protein and mRNA [57]. This is in line with recent findings by Nikitina et al. who observed that high-voltage-activated (HVA) $\mathrm{Ca}^{2+}$ channel currents were significantly decreased and lowvoltage-activated (LVA) currents increased during vasospasm 4, 7, and 21 days after SAH in dogs [28]. This study revealed an increase in protein expression of T-type $\left(\mathrm{Ca}_{v} 3.1\right.$ and $\mathrm{Ca}_{v} 3.3$ alpha subunits) and R-type VGCCs and a decrease in L-type ( $\mathrm{Ca}_{v} 1.2$ and $\mathrm{Ca}_{v} 1.3$ alpha subunits) VGCCs in dog basilar arteries after SAH. Interestingly however, differently to Nikitina et al., Ishiguro et al. could not observe an increase in R-type protein and mRNA in the basilar artery or other larger diameter vessels after SAH, but only in smaller vessels. Several authors suggest that the functional significance of R-type channels may lie within small diameter blood vessels and that blood vessels of different sizes are impacted differently by SAH [58]. Furthermore, exposure of organ cultured rabbit cerebral arteries to oxy $\mathrm{Hb}$ induces the expression of R-type VGCC mRNA in small vessels rendering the vessels sensitive to SNX-482 (R-type antagonist) and less sensitive to diltiazem [59]. SNX-482 was also found to attenuate $\mathrm{CBF}$ reduction after $\mathrm{SAH}$ in rats $[60]$.

In addition to R-type VGCCs, the low-voltage-activated (T-type) channels $\mathrm{Ca}_{v} 3.1$ and $\mathrm{Ca}_{v} 3.3$ have been shown to be upregulated in the dog basilar artery after SAH [28]; however the functional significance of this finding is a matter of debate: the increased expression of $\mathrm{T}$ type VGCC channels was proposed to be functionally irrelevant because these channels should be inactivated in depolarized cells. In fact, T-type channels were reported to inactivate at resting membrane potentials of most smooth muscle cells at about -75 to $-65 \mathrm{mV}$ [17]. Cisternal application of nicardipine but not of the T-type antagonist mibefradil reduced CT angiography measured vasospasm in cynomolgus macaques [61], which is in agreement with the functional insignificance of T-type VGCCs in depolarized cells.

\section{Changes of Ion Channel Expression and Function following Transient Global Ischemia after SAH}

Increased ICP and decreased CPP immediately following SAB cause a transient global ischemia (TGI) [62-64].
Distinguishing which molecular changes can be attributed to subarachnoid blood and which to TGI is difficult; however studies of TGI (without SAH) can be of assistance. Very little is known about changes in ion channel expression and function in cerebral vessels following transient global ischemia. The only study describing direct impact of TGI on ion channels in cerebral arteries found that in piglets arteriolar response (i.e., dilation) of $\mathrm{K}_{\mathrm{ATP}}$ channels to their activators aprikalim and iloprost is impaired 1 hour after TGI but normalizes over 2-4 hours [65]. Interestingly, this reduction of cerebral arteriolar dilation to activation of $\mathrm{K}_{\text {ATP }}$ channels could be prevented with the nonsteroidal anti-inflammatory drug indomethacin. In addition to this acute provasoconstrictive effect, TGI has recently been described to have a delayed provasoconstrictive effect. In the two-vessel carotid artery occlusion model, transient forebrain ischemia caused a functional upregulation of $\mathrm{ET}_{\mathrm{B}}$ and $5-\mathrm{HT}_{1 \mathrm{~B}}$ receptors in the ACA and MCA of the rat 48 hours after the insult [66]. In the case of SAHinduced TGI, an upregulation of vasoconstrictor receptors could contribute to vasospasm and thus to delayed cerebral ischemia.

More is known about the effects of TGI on neuronal ion channels. Transient forebrain ischemia in rats leads to a downregulation of L-type VGCCs in vulnerable hippocampal CA1 neurons by oxidation modulation, whereas L-type $\mathrm{Ca}^{2+}$ channels in the CA3 are not affected [67]. Interestingly, blockade of L-type but not of $\mathrm{N}$ - or P-/ Q-type VGCCs worsened neuronal survival, while, more importantly, L-type calcium-channel agonists applied after reperfusion significantly decreased neuronal injury in rats subjected to forebrain ischemia [67]. These results stand in strong contrast to the widely accepted view of excitotoxic mechanisms after brain ischemia, which make glutamateinduced intracellular calcium overloading responsible for induction of apoptotic proteins and toxic molecules $[68,69]$, but shed light on possible region-specific involvement of calcium signaling in cell survival. Indeed other studies give weight to this hypothesis of L-type downregulation after ischemia and may ultimately lead to a modification of the view of calcium-mediated neurotoxicity [70-72]. R-type VGCCs may also mediate neuroprotection in focal ischemia, as mice lacking the R-type VGCC display larger infarct volume size than wild-type mice after occlusion of the MCA [73]. Although N-type VGCCs (but also L-type, P/Q-type) have been reported to be upregulated in the hippocampus and cortex after global ischemia [74, 75], neuroprotective effectiveness of their inhibitors is a matter of debate, as evidence is contradictory [76]. Furthermore, pharmacologic inhibition of T-type VGCCs has been shown to have a neuroprotective effect in hippocampal neurons after global ischemia in rats and also an in vitro model of ischemiainduced delayed cell death in rat organotypic hippocampal slice cultures [77, 78]. However, a 2012 meta-analysis of effectivity of calcium channel antagonists on ischemic stroke including 7731 patients in 34 trials concluded that calcium channel antagonists have no effect on primary outcome or survival after stroke but that nimodipine at high doses is associated with poorer outcome [79]. 


\section{Conclusions}

It is apparent that the decrease of $\mathrm{K}^{+}$conductance and the shift from $\mathrm{HVA} \mathrm{Ca}^{2+}$ currents to LVA $\mathrm{Ca}^{2+}$ in cerebrovascular myocytes represent key phenomena in SAH-induced vasospasm; however we have yet to put together the pieces to establish a model of the complex mechanisms behind SAH pathology. This paper focuses on ion channels and thus on processes at the cell surface, but one must not overlook the downstream effects of ion channel signaling via interacting proteins like protein kinase $\mathrm{C}$ (PKC), an important regulator of VGCCs. Several VGCCs and nearly all $\mathrm{K}^{+}$channels are highly regulated by PKC. After SAH, hemoglobin alters expression levels of different $\mathrm{PKC}$ isoforms and induces their translocation from the cytosol to the plasma membrane (PKC- $\delta$ on day 4 and PKC- $\alpha$ on day 7) [80]. It has been suggested that $\mathrm{PKC}-\delta$ is involved in initiation of SAHinduced vasospasm whereas PKC- $\alpha$ plays a role in its endurance $[81,82]$. PKC phosphorylates the $\mathrm{Ca}_{v} 1.2$ subunit of L-type calcium channels and leads to dual modulation with inhibitory and stimulatory effects in vascular smooth muscle cells. R-type VGCCs also underlie PKC-mediated $\mathrm{Ca}^{2+}$-dependent stimulation $[83,84]$. But also calmodulin, another regulatory protein of voltage-gated $\mathrm{Ca}^{2+}$ channels, is significantly impacted by $\mathrm{SAH}$, displaying a decrease within the first 48 hours after SAH [85]. One may speculate that imbalance of calmodulin-mediated inactivation and PKC-mediated $\mathrm{Ca}^{2+}$-dependent stimulation of R-type $\mathrm{Ca}^{2+}$ channels might lead to self-perpetuating $\mathrm{Ca}^{2+}$ influx during vasospasm. The calmodulin antagonist trifluoperazine was demonstrated to reduce severity of cerebral vasospasm following SAH but at doses far in excess of the normal accepted therapeutic range in humans [86].

Transient global ischemia after SAH may contribute to neurologic injury by downregulation of L-type VGCCs in the CA1 region of the hippocampus [67] but also may contribute to the occurrence of vasospasm by the increase of vasoconstrictor receptors and the functional impairment of $\mathrm{K}_{\mathrm{ATP}}$ channels in cerebrovascular myocytes $[65,66]$.

In the effort of developing better pharmacologic therapies and prophylaxes of vasospasm, it is very likely that patients will ultimately benefit from in vitro studies investigating ion-channel signaling and protein interaction partners in great detail. As in every disease, identifying exact targets in order to develop specific modulators is key, and the lack thereof may be the root of difficulties in treating vasospasms with L-type antagonists, such as nicardipine or nimodipine, which also have substantial modulatory effects on several other ion channels $[87,88]$. Furthermore, the extent to which vasospasm contributes to poor outcome after $\mathrm{SAH}$ remains a matter of debate. Although several authors falsely cite CONSCIOUS- 1 as evidence that vasospasm does not contribute to poor outcome (the study was not powered to detect changes in morbidity, mortality, or clinical outcome), recent evidence showing that a reduction of cerebral infarction but not of vasospasm correlated with better neurological outcome [89] fuels the debate on causality of the pathological phenomena following SAH. In this regard, it may be necessary to consider further mechanisms by which nimodipine enhances clinical outcome. Several experimental studies of different animal models of cerebral ischemia have found neuroprotective effects of nimodipine [9092]; however clinical studies remain inconclusive. Although nimodipine was found to have no effect on primary outcome or survival after stroke in a recent meta-analysis of 34 clinical trials, one study has found nimodipine to reduce relative risk of the frequency of CT-scan-documented cerebral infarction and of ischemic neurologic deficit after aneurysmal SAH but not of angiographically detected cerebral vasospasm [93]. Taken together, these results underline the need for both experimental and clinical investigations of the molecular mechanisms behind the therapeutic effect of nimodipine and thus calcium channel blockade.

\section{Authors' Contribution}

M. A. Kamp and M. Dibué contributed equally to this work.

\section{References}

[1] C. E. Lovelock, G. J. E. Rinkel, and P. M. Rothwell, "Time trends in outcome of subarachnoid hemorrhage: populationbased study and systematic review," Neurology, vol. 74, no. 19, pp. 1494-1501, 2010.

[2] M. D. Vergouwen, M. Vermeulen, J. van Gijn et al., "Definition of delayed cerebral ischemia after aneurysmal subarachnoid hemorrhage as an outcome event in clinical trials and observational studies: proposal of a multidisciplinary research group," Stroke, vol. 41, no. 10, pp. 2391-2395, 2010.

[3] A. Waters and D. R. Harder, "Altered membrane properties of cerebral vascular smooth muscle following subarachnoid hemorrhage: an electrophysiological study. I. Changes in resting membrane potential $(\mathrm{E}(\mathrm{m}))$ and effect on the electrogenic pump potential contribution to E(m)," Stroke, vol. 16, no. 6, pp. 990-997, 1985.

[4] M. Zuccarello, R. Boccaletti, M. Tosun, and R. M. Rapoport, "Role of extracellular $\mathrm{Ca}^{2+}$ in subarachnoid hemorrhageinduced spasm of the rabbit basilar artery," Stroke, vol. 27, no. 10, pp. 1896-1902, 1996.

[5] M. T. Nelson, J. B. Patlak, J. F. Worley, and N. B. Standen, "Calcium channels, potassium channels, and voltage dependence of arterial smooth muscle tone," American Journal of Physiology-Cell Physiology, vol. 259, no. 1, pp. C3-C18, 1990.

[6] N. B. Standen and J. M. Quayle, " $\mathrm{K}^{+}$channel modulation in arterial smooth muscle," Acta Physiologica Scandinavica, vol. 164, no. 4, pp. 549-557, 1998.

[7] Y. Aihara, B. S. Jahromi, R. Yassari, E. Nikitina, M. AgbajeWilliams, and R. L. Macdonald, "Molecular profile of vascular ion channels after experimental subarachnoid hemorrhage," Journal of Cerebral Blood Flow and Metabolism, vol. 24, no. 1, pp. 75-83, 2004.

[8] S. Chrissobolis, J. Ziogas, Y. I. Chu, F. M. Faraci, and C. G. Sobey, "Role of inwardly rectifying $\mathrm{K}^{+}$channels in $\mathrm{K}^{+}$induced cerebral vasodilatation in vivo," American Journal of Physiology-Heart and Circulatory Physiology, vol. 279, no. 6, pp. H2704-H2712, 2000.

[9] D. Janigro, G. A. West, E. L. Gordon, and H. R. Winn, "ATPsensitive $\mathrm{K}^{+}$channels in rat aorta and brain microvascular endothelial cells," The American Journal of Physiology, vol. 265, no. 3, pp. C812-C821, 1993. 
[10] K. B. Ploug, L. J. Boni, M. Baun, A. Hay-Schmidt, J. Olesen, and I. Jansen-Olesen, "KATP channel expression and pharmacological in vivo and in vitro studies of the KATP channel blocker PNU-37883A in rat middle meningeal arteries," British Journal of Pharmacology, vol. 154, no. 1, pp. 72-81, 2008.

[11] S. Albarwani, L. T. Nemetz, J. A. Madden et al., "Voltage-gated $\mathrm{K}^{+}$channels in rat small cerebral arteries: molecular identity of the functional channels," Journal of Physiology, vol. 551, no. 3, pp. 751-763, 2003.

[12] G. C. Amberg and L. F. Santana, "Kv2 channels oppose myogenic constriction of rat cerebral arteries," American Journal of Physiology-Cell Physiology, vol. 291, no. 2, pp. C348-C356, 2006.

[13] A. N. Poulsen, H. Wulf, A. Hay-Schmidt, I. Jansen-Olesen, J. Olesen, and D. A. Klaerke, "Differential expression of BK channel isoforms and $\beta$-subunits in rat neuro-vascular tissues," Biochimica et Biophysica Acta, vol. 1788, no. 2, pp. 380-389, 2009.

[14] P. D. Smith, S. E. Brett, K. D. Luykenaar et al., "KIR channels function as electrical amplifiers in rat vascular smooth muscle," Journal of Physiology, vol. 586, no. 4, pp. 1147-1160, 2008.

[15] J. J. Zaritsky, D. M. Eckman, G. C. Wellman, M. T. Nelson, and T. L. Schwarz, "Targeted disruption of Kir2.1 and Kir2.2 genes reveals the essential role of the inwardly rectifying $\mathrm{K}^{+}$current in $\mathrm{K}^{+}$-mediated vasodilation," Circulation Research, vol. 87, no. 2, pp. 160-166, 2000.

[16] H. Farr and T. David, "Models of neurovascular coupling via potassium and EET signalling," Journal of Theoretical Biology, vol. 286, no. 1, pp. 13-23, 2011.

[17] G. D. S. Hirst and F. R. Edwards, "Sympathetic neuroeffector transmission in arteries and arterioles," Physiological Reviews, vol. 69, no. 2, pp. 546-604, 1989.

[18] J. M. Quayle, M. T. Nelson, and N. B. Standen, "ATP-sensitive and inwardly rectifying potassium channels in smooth muscle," Physiological Reviews, vol. 77, no. 4, pp. 1165-1232, 1997.

[19] F. M. Faraci and C. G. Sobey, "Role of potassium channels in regulation of cerebral vascular tone," Journal of Cerebral Blood Flow and Metabolism, vol. 18, no. 10, pp. 1047-1063, 1998.

[20] N. Gokina, R. Bevan, C. Walters, and J. Bevan, "Calciumactivated potassium channels regulate membrane potential and tone and modulate action potentials in smooth muscle of human plal arteries," The FASEB Journal, vol. 10, no. 3, p. A301, 1996.

[21] G. C. Wellman, "Ion channels and calcium signaling in cerebral arteries following subarachnoid hemorrhage," Neurological Research, vol. 28, no. 7, pp. 690-702, 2006.

[22] B. E. Robertson, R. Schubert, J. Hescheler, and M. T. Nelson, "cGMP-Dependent protein kinase activates Ca-activated $\mathrm{K}$ channels in cerebral artery smooth muscle cells," American Journal of Physiology-Cell Physiology, vol. 265, no. 1, pp. C299-C303, 1993.

[23] R. M. Hannah, K. M. Dunn, A. D. Bonev, and M. T. Nelson, "Endothelial SKCa and IKCa channels regulate brain parenchymal arteriolar diameter and cortical cerebral blood flow," Journal of Cerebral Blood Flow and Metabolism, vol. 31, no. 5, pp. 1175-1186, 2011.

[24] K. W. Hong, B. Y. Rhim, C. D. Kim, and S. E. Yoo, "Relaxant effects of cromakalim and ATP depletion in dog and rat mesenteric arteries-species differences," Archives Internationales de Pharmacodynamie et de Therapie, vol. 328, no. 1, pp. 54-66, 1994.

[25] N. B. Standen, J. M. Quayle, N. W. Davies, J. E. Brayden, Y. Huang, and M. T. Nelson, "Hyperpolarizing vasodilators activate ATP-sensitive $\mathrm{K}^{+}$channels in arterial smooth muscle," Science, vol. 245, no. 4914, pp. 177-180, 1989.

[26] F. Bari, T. M. Louis, and D. W. Busija, "Effects of ischemia on cerebral arteriolar dilation to arterial hypoxia in piglets," Stroke, vol. 29, no. 1, pp. 222-228, 1998.

[27] E. A. Ko, J. Han, I. D. Jung, and W. S. Park, "Physiological roles of $\mathrm{K}^{+}$channels in vascular smooth muscle cells," Journal of Smooth Muscle Research, vol. 44, no. 2, pp. 65-81, 2008.

[28] E. Nikitina, A. Kawashi, M. Takahashi et al., "Alteration in voltage-dependent calcium channels in dog basilar artery after subarachnoid hemorrhage: laboratory investigation," Journal of Neurosurgery, vol. 113, no. 4, pp. 870-880, 2010.

[29] M. F. Navarro-Gonzalez, T. H. Grayson, K. R. Meaney, L. L. Cribbs, and C. E. Hill, "Non-l-type voltage-dependent calcium channels control vascular tone of the rat basilar artery," Clinical and Experimental Pharmacology and Physiology, vol. 36, no. 1, pp. 55-66, 2009.

[30] E. Nikitina, Z. D. Zhang, A. Kawashima et al., "Voltagedependent calcium channels of dog basilar artery," Journal of Physiology, vol. 580, no. 2, pp. 523-541, 2007.

[31] I. Y. Kuo, A. Ellis, V. A. Seymour, S. L. Sandow, and C. E. Hill, "Dihydropyridine-insensitive calcium currents contribute to function of small cerebral arteries," Journal of Cerebral Blood Flow and Metabolism, vol. 30, no. 6, pp. 1226-1239, 2010.

[32] I. Bezprozvanny and R. W. Tsien, "Voltage-dependent blockade of diverse types of voltage-gated $\mathrm{Ca}^{2+}$ channels expressed in Xenopus oocytes by the $\mathrm{Ca}^{2+}$ channel antagonist mibefradil (Ro 40-5967)," Molecular Pharmacology, vol. 48, no. 3, pp. 540-549, 1995.

[33] P. Miranda, A. Lagares, J. Alen, A. Perez-Nuñez, I. Arrese, and R. D. Lobato, "Early transcranial Doppler after subarachnoid hemorrhage: clinical and radiological correlations," Surgical Neurology, vol. 65, no. 3, pp. 247-252, 2006.

[34] G. A. Schubert, M. Seiz, A. A. Hegewald, J. Manville, and C. Thomé, "Acute hypoperfusion immediately after subarachnoid hemorrhage: a xenon contrast-enhanced CT study," Journal of Neurotrauma, vol. 26, no. 12, pp. 2225-2231, 2009.

[35] T. Westermaier, A. Jauss, J. Eriskat, E. Kunze, and K. Roosen, "Time-course of cerebral perfusion and tissue oxygenation in the first $6 \mathrm{~h}$ after experimental subarachnoid hemorrhage in rats," Journal of Cerebral Blood Flow and Metabolism, vol. 29, no. 4, pp. 771-779, 2009.

[36] T. Hayashi, A. Suzuki, J. Hatazawa et al., "Cerebral circulation and metabolism in the acute stage of subarachnoid hemorrhage," Journal of Neurosurgery, vol. 93, no. 6, pp. 1014-1018, 2000.

[37] B. Romner, B. Ljunggren, L. Brandt, and H. Saveland, "Transcranial Doppler sonography within 12 hours after subarachnoid hemorrhage," Journal of Neurosurgery, vol. 70, no. 5, pp. 732-736, 1989.

[38] R. A. Solomon, M. E. Fink, and L. Lennihan, "Early aneurysm surgery and prophylactic hypervolemic hypertensive therapy for the treatment of aneurysmal subarachnoid hemorrhage," Neurosurgery, vol. 23, no. 6, pp. 699-704, 1988.

[39] Y. Takanashi, B. K. A. Weir, B. Vollrath, H. Kasuya, R. L. Macdonald, and D. Cook, "Time course of changes in concentration of intracellular free calcium in cultured cerebrovascular smooth muscle cells exposed to oxyhemoglobin," Neurosurgery, vol. 30, no. 3, pp. 346-350, 1992.

[40] K. Takenaka, H. Yamada, N. Sakai, T. Ando, Y. Okano, and Y. Nozawa, "Intracellular $\mathrm{Ca}^{2+}$ changes in cultured vascular smooth muscle cells by treatment with various spasmogens," Neurological Research, vol. 13, no. 3, pp. 168-172, 1991. 
[41] K. Takenaka, H. Yamada, N. Sakai et al., "Cytosolic calcium changes in cultured rat aortic smooth-muscle cells induced by oxyhemoglobin," Journal of Neurosurgery, vol. 74, no. 4, pp. 620-624, 1991.

[42] M. Ishiguro, K. Murakami, T. Link et al., "Acute and chronic effects of oxyhemoglobin on voltage-dependent ion channels in cerebral arteries," Acta Neurochirurgica, no. 104, pp. 99-102, 2008.

[43] B. S. Jahromi, Y. Aihara, J. Ai, Z. D. Zhang, E. Nikitina, and R. L. MacDonald, "Voltage-gated $\mathrm{K}^{+}$channel dysfunction in myocytes from a dog model of subarachnoid hemorrhage," Journal of Cerebral Blood Flow and Metabolism, vol. 28, no. 4, pp. 797-811, 2008.

[44] B. S. Jahromi, Y. Aihara, J. Ai et al., "Preserved BK channel function in vasospastic myocytes from a dog model of subarachnoid hemorrhage," Journal of Vascular Research, vol. 45, no. 5, pp. 402-415, 2008.

[45] G. W. Weyer, B. S. Jahromi, Y. Aihara et al., "Expression and function of inwardly rectifying potassium channels after experimental subarachnoid hemorrhage," Journal of Cerebral Blood Flow and Metabolism, vol. 26, no. 3, pp. 382-391, 2006.

[46] M. Ishiguro, A. D. Morielli, K. Zvarova, B. I. Tranmer, P. L. Penar, and G. C. Wellman, "Oxyhemoglobin-induced suppression of voltage-dependent $\mathrm{K}^{+}$channels in cerebral arteries by enhanced tyrosine kinase activity," Circulation Research, vol. 99, no. 11, pp. 1252-1260, 2006.

[47] M. Koide, M. A. Nystoriak, G. Krishnamoorthy et al., "Reduced $\mathrm{Ca}^{2+}$ spark activity after subarachnoid hemorrhage disables BK channel control of cerebral artery tone," Journal of Cerebral Blood Flow and Metabolism, vol. 31, no. 1, pp. 3-16, 2011.

[48] M. T. Nelson and J. M. Quayle, "Physiological roles and properties of potassium channels in arterial smooth muscle," American Journal of Physiology —Cell Physiology, vol. 268, no. 4, pp. C799-C822, 1995.

[49] G. C. Wellman and M. T. Nelson, "Signaling between SR and plasmalemma in smooth muscle: sparks and the activation of $\mathrm{Ca}^{2+}$-sensitive ion channels," Cell Calcium, vol. 34, no. 3, pp. 211-229, 2003.

[50] K. Sugai, T. Yanagisawa, O. Motohashi, M. Suzuki, and T. Yoshimoto, "Levcromakalim decreases cytoplasmic $\mathrm{Ca}^{2+}$ and vascular tone in basilar artery of SAH model dogs," Journal of Cardiovascular Pharmacology, vol. 33, no. 6, pp. 868-875, 1999.

[51] I. Ahmad, S. Imaizumi, H. Shimizu et al., "Development of calcitonin gene-related peptide slow-release tablet implanted in CSF space for prevention of cerebral vasospasm after experimental subarachnoid haemorrhage," Acta Neurochirurgica, vol. 138, no. 10, pp. 1230-1240, 1996.

[52] T. Inoue, H. Shimizu, T. Kaminuma, M. Tajima, K. Watabe, and T. Yoshimoto, "Prevention of cerebral vasospasm by calcitonin gene-related peptide slow-release tablet after subarachnoid hemorrhage in monkeys," Neurosurgery, vol. 39, no. 5, pp. 984-990, 1996.

[53] European CGRP, "Effect of calcitonin-gene-related peptide in patients with delayed postoperative cerebral ischaemia after aneurysmal subarachnoid haemorrhage," The Lancet, vol. 339, no. 8797 , pp. 831-834, 1992.

[54] W. J. Zhao and C. Wu, "Nimodipine attenuation of early brain dysfunctions is partially related to its inverting acute vasospasm in a cisterna magna subarachnoid hemorrhage (SAH) model in rats," International Journal of Neuroscience, vol. 122, no. 10, pp. 611-617, 2012.

[55] A. Kawashima, H. Kasuya, A. Sasahara, M. Miyajima, M. Izawa, and T. Hori, "Prevention of cerebral vasospasm by nicardipine prolonged-release implants in dogs," Neurological Research, vol. 22, no. 6, pp. 634-641, 2000.

[56] C. Thomé, M. Seiz, G. A. Schubert et al., "Nicardipine pellets for the prevention of cerebral vasospasm," Acta neurochirurgica, vol. 110, part 2, pp. 209-211, 2011.

[57] M. Ishiguro, T. L. Wellman, A. Honda, S. R. Russell, B. I. Tranmer, and G. C. Wellman, "Emergence of a R-type $\mathrm{Ca}^{2+}$ channel (Cav 2.3) contributes to cerebral artery constriction after subarachnoid hemorrhage," Circulation Research, vol. 96, no. 4, pp. 419-426, 2005.

[58] M. Ishiguro and G. C. Wellman, "Cellular basis of vasospasm: role of small diameter arteries and voltage-dependent $\mathrm{Ca}^{2+}$ channels," Acta Neurochirurgica, Supplementum, no. 104, pp. 95-98, 2008.

[59] T. E. Link, K. Murakami, M. Beem-Miller, B. I. Tranmer, and G. C. Wellman, "Oxyhemoglobin-induced expression of Rtype $\mathrm{Ca}^{2+}$ channels in cerebral arteries," Stroke, vol. 39, no. 7, pp. 2122-2128, 2008.

[60] F. Wang, Y. H. Yin, F. Jia, and J. Y. Jiang, "Antagonism of Rtype calcium channels significantly improves cerebral blood flow after subarachnoid hemorrhage in rats," Journal of Neurotrauma, vol. 27, no. 9, pp. 1723-1732, 2010.

[61] D. J. Cook, S. Kan, J. L. Ai, H. Kasuya, and R. L. Macdonald, "Cisternal sustained release dihydropyridines for subarachnoid hemorrhage," Current Neurovascular Research, vol. 9, no. 2, pp. 139-148, 2012.

[62] R. Ayer and J. Zhang, "Connecting the early brain injury of aneurysmal subarachnoid hemorrhage to clinical practice," Turkish Neurosurgery, vol. 20, no. 2, pp. 159-166, 2010.

[63] J. B. Bederson, I. M. Germano, and L. Guarino, "Cortical blood flow and cerebral perfusion pressure in a new noncraniotomy model of subarachnoid hemorrhage in the rat," Stroke, vol. 26, no. 6, pp. 1086-1092, 1995.

[64] K. Takagi, Y. Tsuchiya, K. Okinaga, M. Hirata, T. Nakagomi, and A. Tamura, "Natural hypothermia immediately after transient global cerebral ischemia induced by spontaneous subarachnoid hemorrhage," Journal of Neurosurgery, vol. 98, no. 1 , pp. 50-56, 2003.

[65] F. Bari, T. M. Louis, W. Meng, and D. W. Busija, "Global ischemia impairs ATP-sensitive $\mathrm{K}^{+}$channel function in cerebral arterioles in piglets," Stroke, vol. 27, no. 10, pp. 18741880, 1996.

[66] S. Johansson, G. K. Povlsen, and L. Edvinsson, "Expressional changes in cerebrovascular receptors after experimental transient forebrain ischemia," PLoS One, vol. 7, no. 7, Article ID e41852, 2012.

[67] X. M. Li, J. M. Yang, D. H. Hu et al., "Contribution of downregulation of L-type calcium currents to delayed neuronal death in rat hippocampus after global cerebral ischemia and reperfusion," Journal of Neuroscience, vol. 27, no. 19, pp. 52495259, 2007.

[68] J. Guo, F. J. Meng, X. Z. Fu, B. Song, X. B. Yan, and G. Y. Zhang, "N-Methyl-D-aspartate receptor and L-type voltagegated $\mathrm{Ca}^{2+}$ channel activation mediate proline-rich tyrosine kinase 2 phosphorylation during cerebral ischemia in rats," Neuroscience Letters, vol. 355, no. 3, pp. 177-180, 2004.

[69] I. Harukuni and A. Bhardwaj, "Mechanisms of brain injury after global cerebral ischemia," Neurologic Clinics, vol. 24, no. 1, pp. 1-21, 2006.

[70] J. M. Lee, G. J. Zipfel, and D. W. Choi, "The changing landscape of ischaemic brain injury mechanisms," Nature, vol. 399, no. 6738, pp. A7-A14, 1999.

[71] A. Pisani, P. Calabresi, A. Tozzi, V. D’Angelo, and G. Bernardi, "L-type $\mathrm{Ca}^{2+}$ channel blockers attenuate electrical changes and 
$\mathrm{Ca}^{2+}$ rise induced by oxygen/glucose deprivation in cortical neurons," Stroke, vol. 29, no. 1, pp. 196-202, 1998.

[72] I. A. Silver and M. Erecinska, "Intracellular and extracellular changes of $\left[\mathrm{Ca}^{2+}\right]$ in hypoxia and ischemia in rat brain in vivo," Journal of General Physiology, vol. 95, no. 5, pp. 837-866, 1990.

[73] H. Toriyama, L. Wang, H. Saegusa et al., "Role of Cav2.3 ( $\alpha$ IE) $\mathrm{Ca}^{2+}$ channel in ischemic neuronal injury," NeuroReport, vol. 13, no. 2, pp. 261-265, 2002.

[74] Y. H. Chung, C. M. Shin, M. J. Kim, D. H. Shin, Y. B. Yoo, and C. I. Cha, "Spatial and temporal distribution of N-type $\mathrm{Ca}^{2+}$ channels in gerbil global cerebral ischemia," Brain Research, vol. 902, no. 2, pp. 294-300, 2001.

[75] S. K. Park, S. J. An, I. K. Hwang et al., "Temporal alterations in voltage gated $\mathrm{Ca}^{2+}$ channel immunoreactivities in the gerbil hippocampus following ischemic insults," Brain Research, vol. 970, no. 1-2, pp. 87-96, 2003.

[76] A. Azimi-Zonooz, C. B. Kawa, C. D. Dowell, and B. M. Olivera, "Autoradiographic localization of N-type VGCCs in gerbil hippocampus and failure of $\omega$-conotoxin MVIIA to attenuate neuronal injury after transient cerebral ischemia," Brain Research, vol. 907, no. 1-2, pp. 61-70, 2001.

[77] M. Bancila, J. C. Copin, Y. Daali, B. Schatlo, Y. Gasche, and P. Bijlenga, "Two structurally different T-type $\mathrm{Ca}^{2+}$ channel inhibitors, mibefradil and pimozide, protect CA1 neurons from delayed death after global ischemia in rats," Fundamental and Clinical Pharmacology, vol. 25, no. 4, pp. 469-478, 2011.

[78] I. Nikonenko, M. Bancila, A. Bloc, D. Muller, and P. Bijlenga, "Inhibition of T-type calcium channels protects neurons from delayed ischemia-induced damage," Molecular Pharmacology, vol. 68, no. 1, pp. 84-89, 2005.

[79] J. Zhang, J. Yang, C. F. Zhang, X. Q. Jiang, H. Q. Zhou, and M. Liu, "Calcium antagonists foracute ischemic stroke," Cochrane Database of Systematic Reviews. In press.

[80] S. Nishizawa, K. Obara, K. Nakayama et al., "Protein kinase $\mathrm{C} \delta$ and $\alpha$ are involved in the development of vasospasm after subarachnoid hemorrhage," European Journal of Pharmacology, vol. 398, no. 1, pp. 113-119, 2000.

[81] S. Ansar and L. Edvinsson, "Subtype activation and interaction of protein kinase $\mathrm{C}$ and mitogen-activated protein kinase controlling receptor expression in cerebral arteries and microvessels after subarachnoid hemorrhage," Stroke, vol. 39, no. 1, pp. 185-190, 2008.

[82] S. Nishizawa, K. Obara, M. Koide, K. Nakayama, S. Ohta, and T. Yokoyama, "Attenuation of canine cerebral vasospasm after subarachnoid hemorrhage by protein kinase $\mathrm{C}$ inhibitors despite augmented phosphorylation of myosin light chain," Journal of Vascular Research, vol. 40, no. 2, pp. 169-178, 2003.

[83] U. Klöckner, A. Pereverzev, J. Leroy et al., "The cytosolic IIIII loop of Cav2.3 provides an essential determinant for the phorbol ester-mediated stimulation of E-type $\mathrm{Ca}^{2+}$ channel activity," European Journal of Neuroscience, vol. 19, no. 10, pp. 2659-2668, 2004.

[84] A. Stea, T. W. Soong, and T. P. Snutch, "Determinants of PKC-dependent modulation of a family of neuronal calcium channels," Neuron, vol. 15, no. 4, pp. 929-940, 1995.

[85] S. Sakaki, S. Ohue, K. Kohno, and S. Takeda, "Impairment of vascular reactivity and changes in intracellular calcium and calmodulin levels of smooth muscle cells in canine basilar arteries after subarachnoid hemorrhage," Neurosurgery, vol. 25, no. 5, pp. 753-761, 1989.

[86] J. W. Peterson, G. Candia, A. J. Spanos, and N. T. Zervas, "The calmodulin antagonist trifluoperazine provides mild prophylactic protection against cerebral vasospasm after subarachnoid hemorrhage, but no therapeutic value," Neurosurgery, vol. 25, no. 6, pp. 917-922, 1989.

[87] S. Diochot, S. Richard, and J. Valmier, "Diversity of voltagegated calcium currents in large diameter embryonic mouse sensory neurons," Neuroscience, vol. 69, no. 2, pp. 627-641, 1995.

[88] W. Stengel, M. Jainz, and K. Andreas, "Different potencies of dihydropyridine derivatives in blocking T-type but not Ltype $\mathrm{Ca}^{2+}$ channels in neuroblastoma-glioma hybrid cells," European Journal of Pharmacology, vol. 342, no. 2-3, pp. 339345, 1998.

[89] N. Etminan, M. D. I. Vergouwen, and R. L. Macdonald, "Angiographic vasospasm versus cerebral infarction as outcome measures after aneurysmal subarachnoid hemorrhage," Acta Neurochirurgica, vol. 115, pp. 33-40, 2013.

[90] A. I. Korenkov, J. Pahnke, K. Frei et al., "Treatment with nimodipine or mannitol reduces programmed cell death and infarct size following focal cerebral ischemia," Neurosurgical Review, vol. 23, no. 3, pp. 145-150, 2000.

[91] M. Sobrado, M. G. López, F. Carceller, A. G. García, and J. M. Roda, "Combined nimodipine and citicoline reduce infarct size, attenuate apoptosis and increase Bcl-2 expression after focal cerebral ischemia," Neuroscience, vol. 118, no. 1, pp. 107113, 2003.

[92] K. Taya, Y. Watanabe, H. Kobayashi, and M. Fujiwara, "Nimodipine improves the disruption of spatial cognition induced by cerebral ischemia," Physiology and Behavior, vol. 70, no. 12, pp. 19-25, 2000.

[93] V. L. Feigin, G. J. E. Rinkel, A. Algra, M. Vermeulen, and J. van Gijn, "Calcium antagonists in patients with aneurysmal subarachnoid hemorrhage: a systematic review," Neurology, vol. 50, no. 4, pp. 876-883, 1998. 


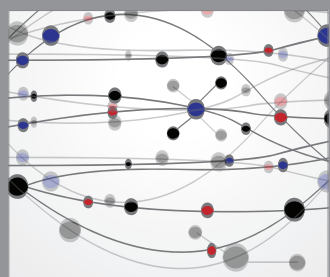

The Scientific World Journal


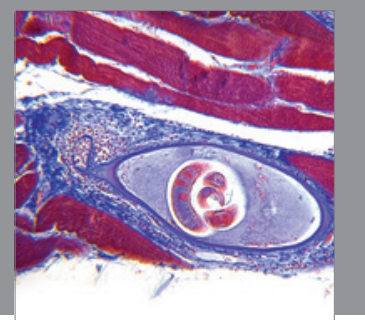

Gastroenterology

Research and Practice


\section{Hindawi}

Submit your manuscripts at

http://www.hindawi.com
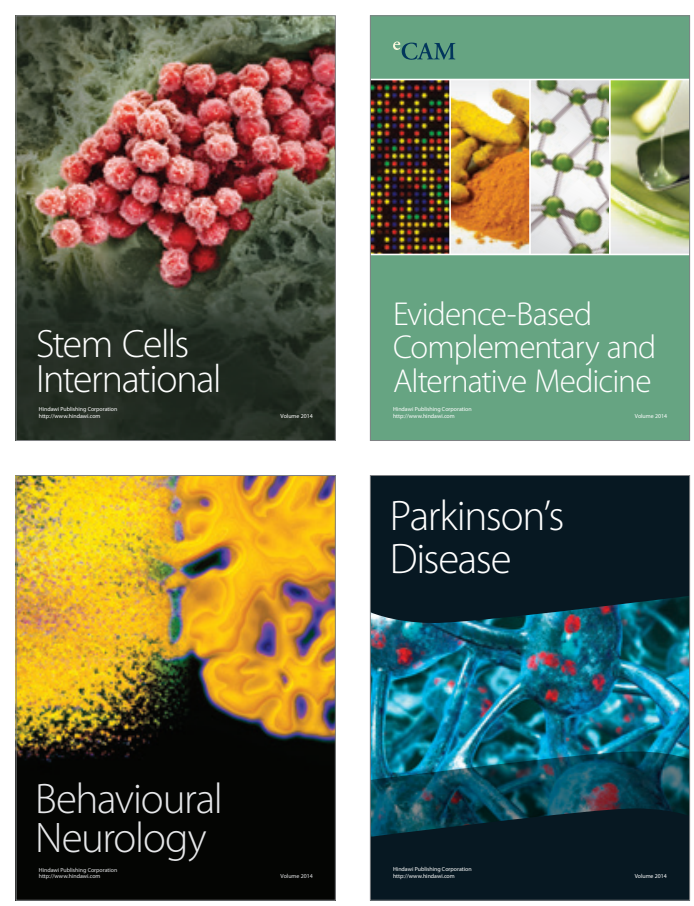

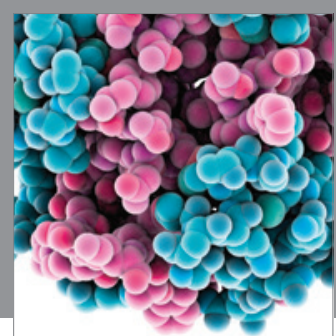

Journal of
Diabetes Research

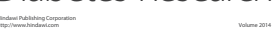

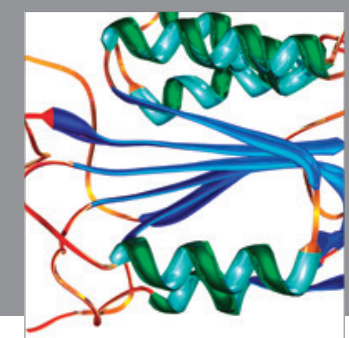

Disease Markers
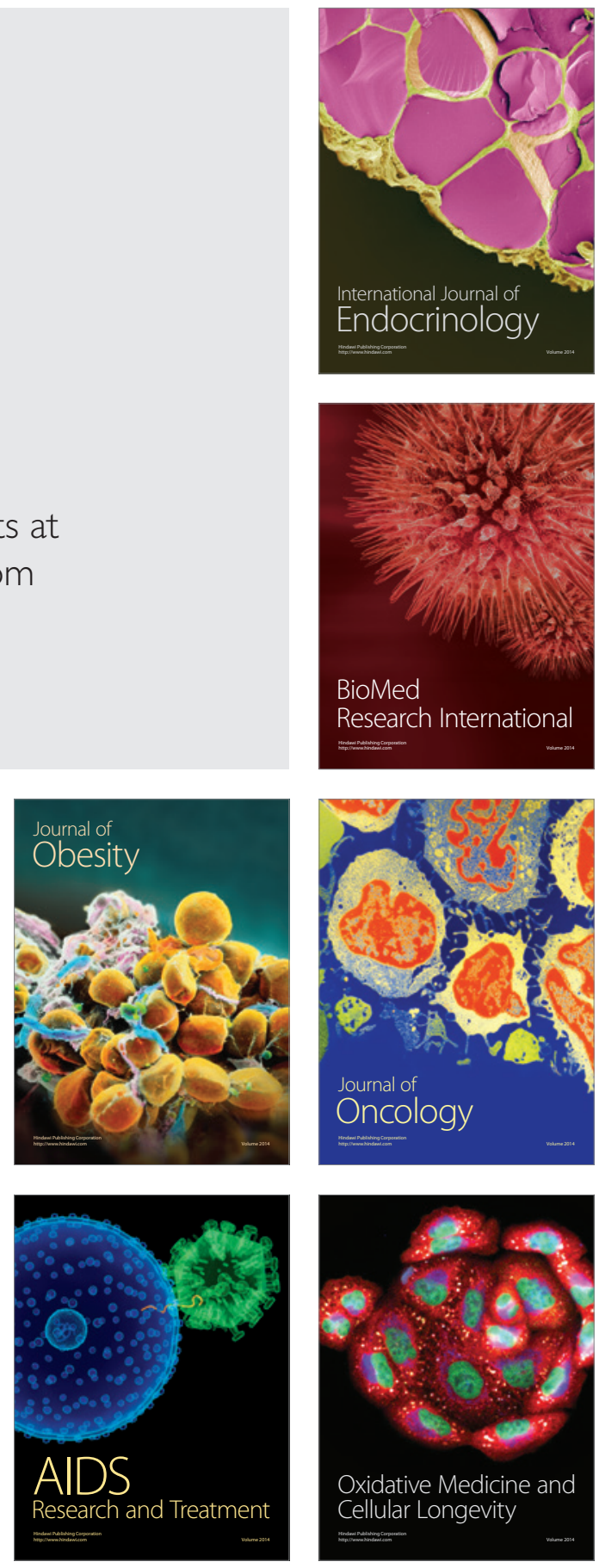